\title{
Enhancing student learning experience in blended classroom teaching
}

\section{Y. Lakshmi Malroutu*}

California State University, Los Angeles, CA

\author{
Keywords \\ technology-enabled \\ Blended classroom learning \\ Student-centered environment \\ Active learning \\ Student success and outcomes
}

Received: 17 October 2017

Accepted: 24 November 2017

Published: 4 December 2017

\begin{abstract}
The exploratory paper will present a case study incorporating active learning classroom teaching and technology and exploring the advantages and challenges they present to both students and faculty. As educational technologies continue to expand, American higher education has witnessed radical transformation to provide students a more integrated and multi-dimensional educational experience. This convergence of technology and student expectations of Generation $\mathrm{Z}$ has led to redefined learning and teaching models. While hitting the sweet spot of technology and learning expectations may need more data and research, the balance can be optimized in blended learning classrooms. Results from the case study indicate that the grade point average increased, and students were satisfied with the blended learning experience, although challenges persisted for both students and faculty. A practical framework to reimagine the role of technology in higher education to create a student-centered ecosystem that empowers learning experiences is presented, along with recommendations on how faculty and institutions could be embracing technology to enhance student outcomes.
\end{abstract}

\section{INTRODUCTION}

At colleges and universities nationwide, a shift is underway where student-centered and technology enabled teaching is being created to meet the needs of students from Generation Z, millennials and other non-traditional students. Since the learning characteristics of Generation $\mathrm{Z}$ or millennials are more adept at technology and expect technology to be part of their social learning experience, colleges and universities are responding with changes to their teaching delivery and student learning ecosystems (Chaiya, Janbanklong and Kerpasit, 2016; Kozinsky, 2017; Yilmaz, 2017). These active learning environments and collaborations between student and faculty are making learning more personalized to today's diverse student. Multiple universities have invested in these emerging learning environments that are transforming higher education landscape. Higher education is replacing older teaching methods with new innovative teaching, leading edge technology and immersive learning environment with the intent to encourage students to be more active participants in the leaning process. Active learning classrooms that utilize blended teaching incorporate technological resources, flexible arrangements and, to some extent, untethered mobility for both student and faculty. The blended classroom teaching encourages interactivity, creativity and supports different learning needs of all students, including students with non-traditional characteristics.

Higher education institutions in the U.S. have worked diligently to align their policies with federal and state policies to promote access, affordability, and graduation in higher

\footnotetext{
${ }^{*}$ Corresponding author: Y. Lakshmi Malroutu

†Email: malroutu@csus.edu
} 
education. They have also supported best practices to support training that is technologyenabled for working learners that promote retraining or skill development. Teaching and learning with imbedded technology tools has given educators the opportunity to rethink the design and delivery to allow for expanded learning and enhance interactions among students, faculty, instructors, peers, and mentors (USA Department of Education, 2017; Shaharuddin, Nawi and Mansor, 2015).

\section{Purpose and Objectives}

The purpose of the exploratory case study is to determine whether blended classroom teaching in a large Personal Finance course at a public university had any impact on student learning success. The objectives of the paper are the following:

1. Factors to consider when selecting a course for blended learning.

2. Determining the success of students in progressing and passing the course.

3. Evaluating the challenges encountered by students and the professor.

4. Ensuring the results of the case study can be scaled up and replicated.

\section{REVIEW OF LITERATURE}

Demographic Changes and Student Expectations

Every generation of students is characterized by experiences that shape their learning behavior and expectations. With Generation $\mathrm{Z}$ entering higher education, they are disrupting the way learning happens by embracing social learning environments where they can be hands-on, engaged and more central in the learning process. They expect on-demand services and more accessibility and equity and seem to thrive when given the opportunity to have a fully immersive educational experience. More than $50 \%$ of students surveyed indicated that they learn best by doing and tend to enjoy class discussions and interactive classroom environments over traditional teaching methodologies. As a digital generation, Generation $\mathrm{Z}$ expects digital learning tools to be deeply integrated into their educational experience. Additionally, they expect course learning tools to be available on-demand and with low barriers to access (Jacolbia, 2015; Kozinsky, 2017). At colleges and universities, educators and administrators are recognizing that the demographic changes will impact the educational paradigm and are redesigning educational experiences to meet the millennial's and Generation Z's hyper connectivity and social media consumption.

\section{Pedagogical Shifts}

New educational ecosystems are being developed at colleges and universities around the county validating the idea that active learning spaces create active minds, expanding the boundaries of learning with classroom experience through engagement, cooperation, and new pedagogical approaches. At the University of Minnesota, Active Learning Classrooms (ALCs), a modification of the SCALE-UP (Student-Centered Active Learning Environment with Upside-down Pedagogies) concept that originated at North Carolina State University, are fostering interactive, flexible, student-centered learning experiences bringing such new dimensions to instruction. Other notable examples of active learning classrooms are the TEAL (Technology-Enabled Active Learning) concept at MIT and the University of Iowa's TILE-Transform, Interact, Learn, Engage (E-Campus News, 2017).

Many colleges, universities and providers of non-institutional learning experiences are using technology to increase accessibility, equity, flexibility, reduce costs, and validate student learning. According to USA Department of Education (2017), equity remains a primary focus in that it ensures that all students have affordable and equitable access to technology enabled blended classrooms and learning experiences. Technology provides the potential and opportunity to improved student outcomes at a lower cost. It can also be leveraged to deliver high-quality learning opportunities at decreased costs and increased 
access to higher education for students who stand to gain the most benefit. Modularized course delivery strategies, adaptive learning platforms, and competency-based models can help students master new skills and allow them to advance toward completion of academic degrees, certifications and other credentials in a cost effective and time efficient manner.

Higher education is also ensuring technology-enabled learning is affordable for students. Some institutions are able to make educational opportunities more widely available at a low cost through digital or open educational resources; yet those savings are not always passed directly to students themselves. Rather than relying on proxies of learning, technology gives us the opportunity to more accurately measure whether students are meeting learning objectives. As existing assessment tools continue to be refined and new instruments to measure learning are developed, they will provide us insight into the pedagogy and practices that support a diversity of students learning needs and the support structures that will enable them to learn. In addition, the digital infrastructure and technology applications used at institutions increasingly make more data available (USA Department of Education, 2017).

Faculty Attitudes on Technology

According to Lederman and Jaschik (2017), in a survey of faculty attitudes on technology, a third (35\%) of instructors said they were "early adopters" of new educational technologies; 55\% said they "typically adopt new technologies after seeing peers use them effectively." Just $10 \%$ were "disinclined to use educational technologies." Nearly two-thirds, $62 \%$, agreed that they fully support the increased use of educational technologies; $8 \%$ disagreed. Faculty members believed online courses are less effective at letting instructors interact with students during class time (86\%); reaching at-risk students (79\%); rigorously engaging students in course material (60\%); maintaining academic integrity (60\%) and delivering necessary content to meet learning objectives (51\%).

While faculty remain convinced that assessment is mainly aimed at satisfying external entities such as accreditors and politicians and are split on whether assessment efforts have improved student learning and completion, more than $40 \%$ of professors are meaningfully involved in planning for use of assessment tools and discussion about assessment information. Seven in ten professors who have taught online say the experience helped them develop skills and practices that improved their teaching. Even more say online teaching has enabled them to think more critically about how to engage students with content, better use multimedia content and better use the learning management system. Roughly half say they are more comfortable using active learning and project-based learning techniques and are better at communicating with students outside class (Lederman and Jaschik, 2017; Supratman, 2015).

\section{Study Framework}

The framework used to elevate students' education paradigm in blended learning is based on the framework presented in the 2017 National Education Technology Plan (USA Department of Education, 2017). This paper utilized the framework to showcase technology enabled teaching improves student outcomes being piloted at California State University, Sacramento. The framework emphasizes a student-centered learning experience while providing better data to educators and administrators and is categorized into four broad categories:

1. Promoting teaching and learning by optimizing blended or active learning classrooms.

2. Assessing the teaching and learning systems for success in coursework, retention and graduation rates. 
4. Creating a leadership pipeline that will continue to support and promote pedagogical and technological innovation.

\section{METHODOLOGY}

The study was conducted in a Personal Finance course, an upper-division course that fulfills major as well as general education requirements at California State University, Sacramento. The course is very popular with students majoring in Business Finance, Economics, Family Studies, Gerontology, Government, Health Science and Science and has high enrollments of approximately 80-120 students per semester. Because of course demand and large class sizes, a decision was made to offer the course as a blended class for the past two semesters.

Students in the blended classroom use an e-text that incorporates multiple financial and hands-on learning tools that students are assigned for each chapter. Students are also expected to come to class having read the chapter or completed the learning tools so that they are able to fully engage in class. Weekly quizzes, midterms exams and finals are taken on-line, and students have the flexibility of taking it at any time on the day the exam is scheduled. The Learning Management System used at the university is Canvas, a platform that is easy to navigate by traditional as well as non-traditional students. There are time limits for the quizzes and exams but no proctoring is done as the goal of these exams is to evaluate students' understanding of financial concepts and their applications and not just rote memorization. Students are permitted to refer to their e-text or notes during the exams.

While the class is taught in a large lecture hall, the space and design of furniture allows for small group interactions and learning. The role of faculty is more of a facilitator and students participate actively and engage throughout the class period. Students are encouraged to ask questions individually or in small groups during class, by email or coming to office hours. After the initial shyness wears off in the first few weeks of the semester, students become more comfortable reaching out to other classmates in class or by Canvas mail where all enrolled student email addresses are readily available. Evaluations are done using formative and summative assessments to determine if the current pedagogical model is achieving student learning outcomes and experiences of students are enriching their learning.

\section{RESULTS AND DISCUSSION}

The key to developing this blended classroom learning is to create a unique, customized and enhanced learning environment where students can be successful. The blended or active learning modality was incorporated for the past two semesters so the sample size is relatively small, approximately 210 students enrolled in the course.

A few significant differences were noted in that the course is well attended each week and student interactions with their peers and the professor was relatively high. Comments and questions posed during class show that students have read the chapter and have attempted to understand the materials. Another helpful tool that support student learning are the hands-on mathematical formulas and exercises that are imbedded within the chapter assignments. Many students complete the exercises before class and have the opportunity to get clarification or their questions answered while interacting in class. Weekly quizzes, midterm and final exams enable the students and the professor to track progress and extend any additional help needed. The grade distributions in the course, compared to previous semesters, indicate that the grade point average increased by 8 points, from a grade of "C+" to a "B." 
Formative and summative assessments conducted during the semester showed that the students, on the most part, were very satisfied with the course and commented that they learned important concepts which were presented in an easy-to-understand format. Students were pleased with the accessibility and flexibility that the e-textbook, online learning tools and online exams and would like to see that replicated in other courses. Students also commented that the weekly quizzes and the hands-on learning tools were very instrumental in their learning and course success. Based on comments received midsemester, course activities and format were adjusted to enable student progress and success. The grades earned in the course indicate students, for the most part, were successful in navigating the course and had a positive learning experience.

The support for faculty endeavors in a blended classroom teaching environment was backed by the university that offers academic technology support through the Division of Information Resources and Technology (IRT) where Learning Management System, video capture, online exams and assessment are supported. IRT also provides on-line and inperson student support and maintains several large computer labs on campus. Working with textbook publisher, Wiley, support for e-textbook was worked out. The Center for Teaching and Learning offers a Summer Teaching Institute where faculty, selected in a competitive process, are provided with a tablet or laptop to work on innovative data informed course redesign. Institutional resources and support have been in place for a long period of time but academic leadership has not yet come up with a model to incentivize innovation in classroom teaching and course redesign. Lack of systematic support infrastructure also leads to sporadic active learning classroom development with faculty finding their own way in seeking support and motivation.

The support for faculty endeavors in a blended classroom teaching environment was backed by the university that offers academic technology support through the Division of IRT where Learning Management System, video capture, online exams and assessment are supported. IRT also provides on-line and in-person student support and maintains several large computer labs on campus. Working with textbook publisher, Wiley, support for e-textbook was worked out. The Center for Teaching and Learning offers a Summer Teaching Institute where faculty, selected in a competitive process, are provided with a tablet or laptop to work on innovative data informed course redesign. Institutional resources and support have been in place for a long period of time but academic leadership has not yet come up with a model to incentivize innovation in classroom teaching and course redesign. Lack of systematic support infrastructure also leads to sporadic active learning classroom development with faculty finding their own way in seeking support and motivation.

As Elmes' (2017) article summarized that the achievement gap reflects a disparity in open enrollment and academic performance based on student's socioeconomic status, race and ethnicity, students in this course represent the diversity in California based on race, ethnicity and academic preparation and the learning environment worked for the majority of students but some of the students struggled in class. The grades and summative evaluations were in line with the success that students experienced in the blended course.

The cost of purchasing or renting the print version of textbook was greatly reduced when the decision was made to move to an e-text. The next step in the process is working with publishers including Wiley and Pearson to have an inclusive access model setup for the course e-text. The e-text will be delivered to students by LMS, Canvas on or before the first day of classes. This will ensure all enrolled students, including those who would have 
delayed or forgone purchasing their course materials due to high costs, have access to the required materials, for a small fee, to succeed in their classes.

Challenges continue to persist within the institutions in scaling up efforts due to lack of faculty and administrative buy-in. Administrators are enthusiastic in endorsing the benefits of active leaning classrooms but do not follow up their endorsements with funding. There is no systematic funding mechanism in place to scale up best practices on campus. Funding to incentivize technology-enabled learning is minimal, so faculty are not motivated to try new teaching modalities. Many faculty are still reluctant to change their teaching styles or do not know how to incorporate changes into their course redesign.

\section{Improve Enhance}
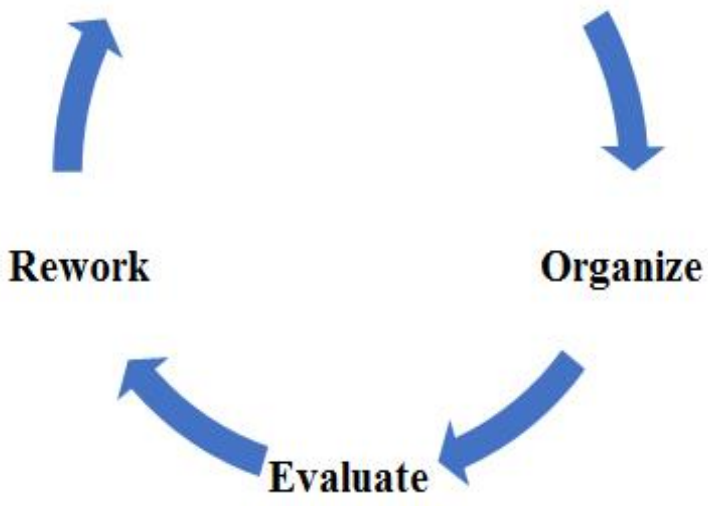

FIGURE 1 . Approach to educational communities

By following this approach, educational communities will reach their own conclusions about how to transform physical space in response. That is how each course will find its own "sweet spot" for student learning success.

\section{CONCLUSION}

Today, colleges and universities offer classes combining the flexibility and personalization of online adaptive learning, the connectedness of an in-class active environment, and enhanced faculty interaction. Students are provided with a technology-rich environment where they can work independently and collaboratively and at the same time have ondemand assistance from faculty, classmates and learning tools. Millennials and Generation Z's ownership of learning may be at an all-time high, moving even higher given the changes in pedagogy toward greater project-based, application-filled discussions and dialogue. Future course design will need to respond to more personalized learning experiences and decision makers will have to address the quality of engagement; that is, determine how users plan to leverage and interact with the technology to which they have access.

The case study presented in this paper has implications for higher education stakeholders who must acknowledge that learning trends will continue to evolve, and they must recognize the relationship between pedagogy, faculty capabilities, physical space, and today's college students' expectations. Students have come to expect flexibility, increased accessibility and to engage with faculty who are willing to create a more personalized learning 
experience.

The implications for higher education institutions and policymakers is that success of their students and institutions rely on their agility to offer student-centered, problembased, mobile, blended or hybrid learning that can scale-up effective best practices. Institutions must be committed to faculty development and support to create technologyenabled teaching and learning to enhance their students' enrollment, retention and graduation rates. Faculty members are a critical element to classroom success, but they are often not given the freedom to select learning tools to drive optimal pedagogical success, due to large class sizes, space limitations, availability of resources, and lack of infrastructure.

Policymakers must earmark and designate state appropriation funding, in a systematic and ongoing manner, for e-learning platforms and to expand active learning classroom teaching. Future research of blended classroom learning must be replicated in different courses and in different institutions to fully understand the efficacy of these learning paradigms. Educators and academic leaders must explore their own unique variables in order to optimize the learning experience for their students.

\section{LIMITATIONS AND RECOMMENDATIONS}

The findings have some potential limitations. For instance, a challenge is that the blended classroom teaching is not a one-solution-fits-all model and different fields have different expectations. Science, Technology, Engineering and Mathematics (STEM ); Science, Technology, Engineering, Arts and Mathematics (STEAM); Science, Technology, Engineering and Mathematics-Health (STEM-H ) will have to develop their own models of technologyenabled education systems which makes it more challenging. Thus, more research in this domain os required in future.

Educators who are interested in creating blended classrooms would benefit from the following recommendations to help shape successful classroom designs for their students:

- Understanding the needs of students and being responsive to the dynamics within the blended classroom environment.

-While the needs of different fields are varied, the core of blended learning model remains the same and could be used to scale-up best practices.

- Faculty can start small using simplified concepts when introducing blended learning in classes.

- Faculty success depends on working with key stakeholders including campus Information Technology personnel, textbook publishers, other faculty familiar with e-learning, potential employers and students to organize and improve their course redesign.

- Enhance. Organize. Observe. Rework. Improve. And repeat it until the model is refined so that class redesign and blended learning environment are aligned with pedagogy and technology.

\section{REFERENCES}

Chaiya, K., Janbanklong, T., and Kerpasit, P. 2016. Factors affecting policy implementation of student loan funds, case study: Suan Sunandha Rajabhat University. International Journal of Business and Administrative Studies 2, no. 5: 118-123. DOI: 10.20469 /ijbas.2.10001-5

E-Campus News. 2017. A shift to active learning environments. E-campus news-technology news and innovation in higher education. URL: https://bit.ly/2H7RRUG (accessed on February 25, 2017) 
Elmes, J. 2017. Six significant challenges for technology in higher education in 2017. What will hold back the use of technology in higher education over the next five years? URL: https://bit.ly/2H5Y7jN (accessed on February 16, 2017)

Jacolbia, R. B. 2015. Gender equality learning materials methods and strategies subject matter evaluation. Journal of Ad- vances in Humanities and Social Sciences 1, no. 1: 9-18. D0I: 10.20474/jahss1.1.2

Kozinsky, S. 2017. How generation $\boldsymbol{Z}$ is shaping the change in education. URL: https://bit.ly/2ETNv1l (accessed on July $24,2017)$

Lederman, D. and Jaschik S. 2017. Professors' changing views of digital learning results from the 2017 inside higher Ed/gallup survey of faculty attitudes on technology. URL: https://bit.ly/2H5Z5MX (accessed on November 16, 2017)

Shaharuddin, Shahida, Nawi Farah Amalina Md, and Mansor Maslina. 2015. Understanding factors that affect level of oral communication apprehension between accounting and non-accounting students: A literature review. International Journal of Business and Administrative Studies 1, no. 1: 1- 4. D0I: /10.20469/ijbas.10001

Supratman, Lucy Pujasari, 2015. A case study of classroom seating arrangement to promote students' communication and interactivity in Telkom University. International Journal of Humanities, Arts and Social Sciences 1, no. 3: 130-133.

DOI: /10.20469/ijhss.20005-3

USA Department of Education. 2017. Reimagining the role of technology in higher education a supplement to the Na- tional education technology plan. URL: https://bit.ly/2jqz5fo (accessed on January 13, 2017).

Yilmaz, Devrim Vural. 2017. International student recruitment in policy and practice: A research from Turkey. Journal of Advanced Research in Social Sciences and Humanities 2, no. 1: 01-08. D0I: 10.26500/jarssh-02-2017-0101 